\title{
Prognostic Value of Exercise Capacity in Incidence Diabetes: A Country With High Prevalence of Diabetes
}

\author{
Abdelrahman A. Jamiel ( $\sim$ abdujamiel@yahoo.com ) \\ King Abdulaziz Medical City \\ Husam Ardah \\ King Abdullah International Medical Research Center \\ Amjad M. Ahmed \\ King Abdulaziz Medical City \\ Mouaz H. Al-Mallah \\ Houston Methodist DeBakey Heart \& Vascular Center
}

Research Article

Keywords: Incidence Diabetes, Exercise Capacity, Metabolic equivalent of tasks (METs), Net reclassification index, Predictive modeling

Posted Date: December 13th, 2021

DOI: https://doi.org/10.21203/rs.3.rs-1147869/v1

License: (c) (i) This work is licensed under a Creative Commons Attribution 4.0 International License. Read Full License 


\section{Abstract}

Background: Diabetes Mellitus (DM) is a fast-growing health problem that imposes an enormous economic burden. Several studies demonstrated the association between physical inactivity and predicting the incidence of diabetes. However, these prediction models have limited validation locally. Therefore, we aim to explore the predictive value of exercise capacity in the incidence of diabetes within a high diabetes prevalence population.

Methodology: A retrospective cohort study including consecutive patients free of diabetes who underwent clinically indicated treadmill stress testing. Diabetic patients at baseline or patients younger than 18 years of age were excluded. Incident diabetes was defined as an established clinical diagnosis post-exercise testing date. The predictive value of exercise capacity was examined using Harrell's c-index, net reclassification index (NRI), and integrated discrimination index (IDI).

Results: A total of 8,722 participants (mean age $46 \pm 12$ years, $66.3 \%$ were men) were free of diabetes at baseline. Over a median follow-up period of 5.24 (2.17-8.78) years, there were $2,280(\approx 26 \%)$ new cases of diabetes. In a multivariate model adjusted for conventional risk factors, we found a $12 \%$ reduction in the risk of incident diabetes for each one greater $\mathrm{MET}$ achieved $(\mathrm{HR}, 0.9 ; 95 \% \mathrm{Cl}, 0.88-0.92 ; \mathrm{P}<0.001)$. Using Cox regression, exercise capacity improved the prediction ability beyond the conventional risk factors ( $\mathrm{AUC}=0.62$ to 0.66 and $\mathrm{c}$-index $=0.62$ to 0.68 ).

Conclusion: Exercise capacity improved the overall predictability of incidence diabetes. Patients with reduced exercise capacity are at high risk for developing incidence diabetes. Improvement of both physical activity and functional capacity represents a preventive measure for the general population.

\section{Introduction}

Diabetes is a major socio-economic health problem with prevalence continues to increase globally over the past decades ${ }^{1-3}$. Prevention of diabetes is a crucial health priority ${ }^{4}$. Strong evidence engaging higher levels of exercise capacity and lifestyle interventions has shown a protective impact on subsequent diabetes ${ }^{5-9}$. Physical activity influences both cardiorespiratory fitness (CRF), which reflects the wellbeing of the cardiovascular system, and muscular strength ${ }^{10-13}$. The significance of this evidence has led several organizations, including the American Heart Association, the American Diabetes Association, and the US. Department of Health and Human Services to include exercise capacity in their recommendations and guidelines ${ }^{14}$. However, it remains controversial how other diabetes-related risk factors, especially metabolic syndrome elements, might alter the association between fitness and incident diabetes ${ }^{15-18}$

The actual effect of exercise capacity on diabetes has not been fully explored as most previous data exemplify nations with low to intermediate disease prevalence ${ }^{19,20}$. These data reflect societies where the culture of Exercise is dominant, while in the Middle East and North Africa (MENA) a rise in prevalence is likely to occur in light of low activity levels among citizens. Therefore, the purpose of this study was to extend the exploration of the predictive value of exercise capacity in incidence diabetes through 1) examine the relationship between exercise capacity and incident diabetes among patients free of diabetes at baseline and 2) examine whether the relationship between CRF and incident diabetes differed across demographic characteristics and other traditional diabetes-related risk factors. Furthermore, we assess the relationship between Duke Treadmill Score, exercise capacity, and incidence of diabetes.

\section{Methods}

\section{Study design and population}

A retrospective cohort study included consecutive patients who underwent clinically indicated exercise treadmill stress testing at King Abdulaziz cardiac center between April 2001 and December 2016. Baseline demographics, past medical history, and medications at the stress test were obtained by reviewing the electronic medical record and database search using the ICD-9 coding system. Data about the exercise stress testing were collected from the stress testing unique system (MUSE). Patients who had diabetes at the baseline before exercise stress testing, patients younger than 18 years, records with incomplete stress testing information, and non-Bruce protocol exercise stress testing were excluded from the study analysis. The study was conducted in full accordance with the protocol and the current revision of the declaration of Helsinki, the Good Clinical Practice. The study was a part of the Saudi CArdioRespiratory Fitness (SCARF) project (Study protocol: RC16/103/R - approved by King Abdullah International Medical Research Center (KAIMRC)).

\section{Exercise treadmill stress testing}

Patients underwent symptom-limited maximal treadmill stress testing, which followed the standard Bruce protocol. The test day was pointed as the individual study baseline. Individuals' results of the initial exercise test were included in the database. Resting measures, heart rate, and blood pressures were measured in the seated position and were recorded immediately before each test initiation. Supervised clinicians were following American Heart Association/American College of Cardiology (AHA/ACC) guidelines for terminating the test if the patient had Exercise limiting symptoms: chest pain, shortness of breath, significant arrhythmias, abnormal hemodynamic responses, diagnostic ST-segment changes, other limiting symptoms independent of the achieved heart rate or if the participant was unwilling or unable to continue. Otherwise, patients could reach their peak attainable workload independent of the heart rate achieved. Target heart rate was calculated as $85 \%$ of the age-predicted maximal heart rate, which is the patient age 
subtracted from a constant value of 220. Metabolic equivalents (METs) were adopted to represent cardiorespiratory fitness status based on the workload derived from the maximal speed and grade achieved during the total treadmill time. METs results were categorized into four groups: $<6,6-9$, $10-11$, and $\geq 12$ METs.

\section{Study definitions for risk factors}

The history of hypertension was defined as a prior diagnosis of hypertension or the use of antihypertensive medications at the time of stress testing. Dyslipidemia was defined as the prior diagnosis of any significant lipid abnormality in the medical records or lipid-lowering medication use. On a prior angiogram, patients with obstructive coronary artery disease (CAD), prior myocardial infarction, coronary angioplasty, or coronary artery bypass surgery are considered known coronary artery disease. Prior congestive heart failure was defined as a prior clinical diagnosis of systolic or diastolic heart failure.

\section{Study outcome: Incident Diabetes}

Incident diabetes was determined among patients without diabetes at baseline and defined as clinical diagnosis of diabetes in the medical records or clinical problem list, use of anti-hyperglycemic medications including insulin, or had lab results suggestive of diabetes post-exercise testing date. Timeto-incident diabetes was based on the time between treadmill testing and the date of the first encounter with a new diabetes diagnosis.

\section{Statistical analysis plan}

Study participants were divided into four groups based on their METs $(<6,6-9,10-11$, and $\geq 12)$. Categorical variables were presented in frequencies and percentages. Continuous variables were presented base on the normality of distribution as mean \pm standard deviation or median and interquartile ranges, overall and in categories of METs. The four groups were compared using Chi-square or Fisher exact test for categorical variables. Analysis of Variance (ANOVA) and Kruskal Wallis test were used for continuous variables compersion, as appropriate. Cumulative incidence was presented at 5-, 10-, and 15-yr intervals via a bar graph.

Kaplan-Meier cumulative incident diabetes was computed for different exercise capacity groups, and they were compared using the log-rank test. Cox regression was used to compute hazard ratios (HR) and $95 \%$ confidence intervals (Cl). A forward selection technique was used to demonstrate independent predictors of incident diabetes. In each forward step, we added a related set of variables to improve our model. Therefore, gender, age, and heart rate were included in the baseline model (model 1). Subsequently, hypertension, hyperlipidemia, smoking, lung disease, previous coronary artery disease and previous congestive heart failure (model 2), antihypertensive medications, lipid-lowering medications, and proton pump inhibitors (model3), METs achieved, chronotropic incompetence, and Duke score (model 4). The primary analysis assessed the association between exercise capacity and time-free event of incident diabetes after adjusting for baseline clinical and cardiovascular risk factors. In the baseline model, we included age, gender. Subsequently, cardiovascular risk factors and related cardiac medications (Model 2), METs groups (Model 3) were added to the baseline model. We computed Harrell's concordance index (C-index) area under the Curve (AUC) and Akaike information criterion (AIC) to compare the models using this methodology developed for incidence diabetes. The selection of variables for entry consideration was based on clinical judgment, results of previous publications, and the expertise of the investigators. We also plotted a restricted cubic spline model to show the shape of the continuous relationship between METs and incident diabetes after adjustment for covariates. Finally, we examined the association between METs and incident diabetes in the subset of participants with a BMI measurement $(\mathrm{N}=6,539)$ (Supplementary Table 1). All Statistical analyses were conducted using SAS 9.4 (SAS Institute Inc., Cary, NC, USA). Statistical significance was defined as $P \leq 0.05$.

\section{Results}

Our study included 8,722 participants without diabetes at baseline. The mean age of study participants was $46 \pm 12$ years, and $66.5 \%$ were men; $33.9 \%$ were hypertensive; $28.3 \%$ had hyperlipidemia; $5.4 \%$ were known to have prior coronary artery disease (CAD), and only a few of them had heart failure (Table 1).

Participants with the highest exercise capacity ( $\geq 12 \mathrm{METs}$ ) were younger ( $41 \pm 3$ vs. $51 \pm 12$ years, $p<0.001)$; more often males ( $91 \%$ versus $43 \%, p<0.001$ ); had lower mean body mass index ( $26 \pm 9$ vs. $\left.32 \pm 3 \mathrm{~kg} / \mathrm{m}^{2}, p<0.001\right)$ and less likely to have hypertension or hyperlipidemia $(26 \%$ vs. $44 \%$ and $25 \%$ vs. $29 \%$, respectively, $p<0.001)$ in comparison with the lowest exercise capacity group (METs<6). No apparent differences between CRF categories regarding prior coronary artery disease (CAD) and heart failure were observed. At peak exercise, the heart rate was higher among the highest achievers (166 \pm 2 vs. $131 \pm 25 \mathrm{bpm}, p<0.001)$ as well as systolic blood pressure $(161 \pm 21 \mathrm{vs} .153 \pm 33 \mathrm{mmHg}, p<0.001)$. Moreover, The highest METs was associated with a lower risk of Duke Treadmill risk, while high Duke Treadmill risk was observed in those with lower METs achieved (for low Duke score: $77.2 \%$ vs. $19.4 \%$ ) and (for high Duke score $0.7 \%$ vs. $2.7 \%$ ), $p<0.001$.

Over a median follow-up period of 5.24 (IQR: 2.17-8.78) years, there were 2,280 (25.96\%) new cases of diabetes. The unadjusted 5-year accumulative incidence rates of diabetes across categories of $\operatorname{CRF}(<6,6<9,10<11$, and $\geq 12$ METs) were $25.1 \%, 16.9 \%$, $9.4 \%$, and $6.2 \%$, respectively. The cumulative rates of incidence of diabetes by the end of 15 years follow up period was as follows: $40.6 \%, 31.9 \%, 23.2 \%$, and $17.3 \%$ for those who achieved $<6,6<9$, $10<11$, and $\geq 12$ METs, respectively (Figure 1 ). 
Examination of the crude association between categories of METs and risk for incident diabetes using a Kaplan-Meier cumulative incidence curve revealed a significant trend across categories of METs (log-rank <0.001) (Figure 2). In a multivariate Cox regression model adjusted for potential confounders, we found a $10 \%$ reduction in the risk of incident diabetes with higher METs achieved (HR, 0.90; 95\% Cl, 0.88-0.92; $p<0.001)$ (model 4B) and risk for incident diabetes reduced per each METs achieved; $13 \%$ ( $6<9$ METs), 38\% (10<11), and $52 \%$ ( $\geq 12$ METs) compare to lower METs ( $<6$ METs) $p<0.001$. Adding the exercise capacity information (METs achieved, $\mathrm{Cl}$, and Duke Risk score) improves the overall predictability of the model (model $4 \mathrm{~A}$ ) over the baseline model (Table 2). We examined the predictive value of the finding of exercise stress testing, and we found superiority of METs groups in prediction incidence diabetes above the other models resulted in a significant reclassification of the study cohort and significant improvement of the area under the curve above the primary model (Table 2)

A non-linear inverse relationship was observed between baseline exercise capacity and risk of incident diabetes after adjusted for known cofounders. A gradual decline in the risk of development of diabetes was observed for every improvement of exercise capacity (METs increase) above 6 METs (Figure 3)

\section{Discussion}

In this study, we investigated the relationship between CRF level and the development of type 2 diabetes among Saudi patients. To the best of our knowledge, this is the first large and demographically diverse cohort to examine the association between CRF estimated by METs using a standard test (Bruce protocol) by exercise treadmill testing and risk of incident diabetes in the Saudi population. We have shown that higher fitness was strongly associated with a lower risk of diabetes among patients without diabetes at baseline, such that every increment of fitness by 1 MET was associated with a $12 \%$ lower risk of developing diabetes. Another important finding in our study was the inverse linear relationship between CRF and diabetes, which notably did not show evidence of plateauing or reversal at higher levels of CRF. This association was observed regardless of age, sex, and other common diabetes-related risk factors.

Several small cross-sectional studies have shown that exercise capacity is inversely associated with impaired glycemic control ${ }^{21}$, the metabolic syndrome ${ }^{22}$, diabetes ${ }^{23,24}$ and positively associated with glucose disposal rate ${ }^{25}$ and insulin sensitivity ${ }^{26}$. Unfortunately, these studies have been small and confined to limited demographic settings (single-sex, racial group, or age-group). To our knowledge, only two prospective studies have been conducted on the relationship between cardiorespiratory fitness level and the incidence of type 2 diabetes ${ }^{27,28}$. Lynch et al. ${ }^{29}$ reported that Finnish men with a higher cardiorespiratory fitness level, measured using a bicycle ergometer, had a significantly lower risk of developing type 2 diabetes over the 4year follow-up period. In a study of U.S. men with the study group consisting primarily of Caucasian men, Wei et al. ${ }^{30}$ found a significant inverse relationship between cardiorespiratory fitness (measured by treadmill time) and the incidence of type 2 diabetes. Moreover, previous studies utilized self-reported PA as a surrogate for fitness. PA represents behavior and may not reflect one's health compared to CRF.

The mechanism that links the relationship between fitness and incident diabetes is a subject of much discussion. Sato et al. ${ }^{31}$ demonstrated that individuals with low cardiorespiratory fitness have high insulin resistance. Additionally, Ivy and Kuo ${ }^{32}$ reported that individuals with lower levels of CRF have fewer glucose transporters compared with those more fit. It is thought that this relationship is mediated by positive changes in one's body tissue profile, namely, 1) reduced adiposity, a significant risk factor for diabetes ${ }^{33}$, increased skeletal muscle, a critical tissue in postprandial glucose uptake ${ }^{25}$,

${ }^{34}$. Moreover, higher fitness has been shown to increase insulin sensitivity and glucose disposal directly35. However, it is also possible that fitness partly reflects one's native genetic state ${ }^{36}$ independent of physical activity. For example, several studies have shown that impaired oxidative respiration due to mitochondrial dysfunction ${ }^{37}$ underlies the pathogenesis of diabetes. Such a state would also manifest as reduced fitness independent of one's physical activity.

\section{Study Limitations and Strengths}

Our study is not without limitations. First, cardiovascular health is independently associated with behaviors that may represent the causal contributing to fitness. Unfortunately, we are unable to assess these behaviors in our study formally. Second, incident diabetes was based on medical records and administrative claims files, which were not collected initially to examine diabetes. As a result, our study did not include study protocol-based direct measurements of hemoglobin A1c, blood glucose, or oral glucose tolerance testing. Because of this, several people with undiagnosed diabetes may have been included in our study population or missed as incident cases, attenuating our results. Third, our study population comprised persons referred for stress testing, which undoubtedly carries a higher burden of cardiovascular disease at baseline than the general population and may have led to referral bias. That limits our study's generalizability. Fourth, residual confounding is always a concern with observational studies, especially with covariates assessed via the medical record rather than a direct measurement. Finally, our study reports a single center's experience with its unique practice patterns and mode of operation. Thus, although the cohort studied was diverse, it may not represent the entire adult population of Saudi Arabia.

On the other hand, our study has some strengths. The standard stress testing, the Bruce protocol treadmill test, characterized fitness rather than selfreporting physical activity. This way is readily interpreted in clinical settings. Furthermore, our study sample was a large and diverse sample, which adequately powered our study.

\section{Conclusion}


In conclusion, our results showed a strong inverse relationship between cardiorespiratory fitness and the development of type 2 diabetes. This relationship was independent of other traditional risk factors for diabetes. This study provides further supporting evidence of the benefits of higher overall fitness. Maintaining a high cardiorespiratory fitness level may contribute to the prevention of type 2 diabetes; therefore, we hope our findings will encourage health professionals to advise the general public and diabetics to lead an active lifestyle and improve their fitness levels. Prospective future studies are required to evaluate these findings further.

\section{Abbreviations}

1. CRF: Cardiorespiratory fitness

2. MENA: Middle East and North Africa

3. SCARF project: Saudi CArdioRespiratory Fitness project

4. AHA/ACC: American Heart Association/American College of Cardiology

5. METs: Metabolic equivalents

6. CAD: Coronary artery disease

7. ANOVA: Analysis of Variance

8. HR: Hazard ratios

9. Cl: confidence intervals

10. AIC: Akaike information criterion

11. AUC: Area under the Curve

12. C-index: Concordance index

\section{Declarations}

- Ethics approval and consent to participate: The study protocol and waved consent were approved by ethical committee of King Abdullah International Medical Research Center (KAIMRC). Study protocol number : RC16/103/R

- Consent for publication: Not applicable.

- Availability of data and materials: The datasets generated are not for publicly sharing according to the policy declared by KAIMRC in Riyadh-Saudi Arabia and a data sharing agreement has to be signed for that on reasonable request.

- Competing interests: The authors declare that there are no competing interests.

- Funding: The study has no funding.

- Authors' contributions: All authors were contributed equally to all stages of the study and agree on the final version of the manuscript.

- Acknowledgements: None

- Conflicts of interest: Nothing to declare

\section{References}

1. Zhou B, Lu Y, Hajifathalian K, Bentham J, Di Cesare M, Danaei G, et al. Worldwide trends in diabetes since 1980: a pooled analysis of 751 population-based studies with $4 \cdot 4$ million participants. The Lancet. 2016;387(10027):1513-30.

2. Cowie CC, Rust KF, Byrd-Holt DD, Gregg EW, Ford ES, Geiss LS, et al. Prevalence of diabetes and high risk for diabetes using A1C criteria in the US population in 1988-2006. Diabetes care. 2010;33(3):562-8.

3. Roglic G, Unwin N. Mortality attributable to diabetes: estimates for the year 2010. Diabetes research and clinical practice. 2010;87(1):15-9.

4. Torjesen I. NHS England rolls out world's first national diabetes prevention programme. British Medical Journal Publishing Group; 2016.

5. Church TS, Blair SN, Cocreham S, Johannsen N, Johnson W, Kramer K, et al. Effects of aerobic and resistance training on hemoglobin A1c levels in patients with type 2 diabetes: a randomized controlled trial. Jama. 2010;304(20):2253-62.

6. Aune D, Norat T, Leitzmann M, Tonstad S, Vatten LJ. Physical activity and the risk of type 2 diabetes: a systematic review and dose-response meta-analysis. Springer; 2015.

7. Kyu HH, Bachman VF, Alexander LT, Mumford JE, Afshin A, Estep K, et al. Physical activity and risk of breast cancer, colon cancer, diabetes, ischemic heart disease, and ischemic stroke events: systematic review and dose-response meta-analysis for the Global Burden of Disease Study 2013. bmj. 2016;354:i3857.

8. Lin X, Zhang X, Guo J, Roberts CK, McKenzie S, Wu WC, et al. Effects of exercise training on cardiorespiratory fitness and biomarkers of cardiometabolic health: a systematic review and meta-analysis of randomized controlled trials. Journal of the American Heart Association. 2015;4(7):e002014.

9. Group DPPR. Long-term effects of lifestyle intervention or metformin on diabetes development and microvascular complications over 15-year follow-up: the Diabetes Prevention Program Outcomes Study. The lancet Diabetes \& endocrinology. 2015;3(11):866-75.

Page 5/12 
10. Sigal RJ, Kenny GP, Wasserman DH, Castaneda-Sceppa C. Physical activity/exercise and type 2 diabetes. Diabetes care. 2004;27(10):2518-39.

11. Jeon CY, Lokken RP, Hu FB, Van Dam RM. Physical activity of moderate intensity and risk of type 2 diabetes: a systematic review. Diabetes care. 2007;30(3):744-52.

12. Williams PT. Vigorous Exercise, fitness and incident hypertension, high cholesterol, and diabetes. Medicine and science in sports and Exercise. 2008;40(6):998.

13. Hu G, Jousilahti P, Barengo NC, Qiao Q, Lakka TA, Tuomilehto J. Physical activity, cardiovascular risk factors, and mortality among Finnish adults with diabetes. Diabetes care. 2005;28(4):799-805.

14. Colberg SR, Sigal RJ, Fernhall B, Regensteiner JG, Blissmer BJ, Rubin RR, et al. Exercise and type 2 diabetes: the American College of Sports Medicine and the American Diabetes Association: joint position statement. Diabetes care. 2010;33(12):e147-e67.

15. Wei M, Gibbons LW, Mitchell TL, Kampert JB, Lee CD, Blair SN. The association between cardiorespiratory fitness and impaired fasting glucose and type 2 diabetes mellitus in men. Annals of internal medicine. 1999;130(2):89-96.

16. Aadahl M, Kjær M, Kristensen JH, Mollerup B, Jørgensen T. Self-reported physical activity compared with maximal oxygen uptake in adults. European Journal of Cardiovascular Prevention \& Rehabilitation. 2007;14(3):422-8.

17. Blaha MJ, Hung RK, Dardari Z, Feldman DI, Whelton SP, Nasir K, et al. Age-dependent prognostic value of exercise capacity and derivation of fitness-associated biologic age. Heart. 2016;102(6):431-7.

18. Sato Y, Iguchi A, Sakamoto N. Biochemical determination of training effects using insulin clamp technique. Hormone and metabolic research. 1984;16(09):483-6.

19. Sawada SS, Lee I-M, Muto T, Matuszaki K, Blair SN. Cardiorespiratory fitness and the incidence of type 2 diabetes: prospective study of Japanese men. Diabetes care. 2003;26(10):2918-22.

20. Sui X, Hooker SP, Lee I-M, Church TS, Colabianchi N, Lee C-D, et al. A prospective study of cardiorespiratory fitness and risk of type 2 diabetes in women. Diabetes care. 2008;31(3):550-5.

21. Fang ZY, Sharman J, Prins JB, Marwick TH. Determinants of exercise capacity in patients with type 2 diabetes. Diabetes care. 2005;28(7):1643-8.

22. Finley CE, LaMonte MJ, Waslien Cl, Barlow CE, Blair SN, Nichaman MZ. Cardiorespiratory fitness, macronutrient intake, and the metabolic syndrome: the Aerobics Center Longitudinal Study. Journal of the American Dietetic Association. 2006;106(5):673-9.

23. Williams PT. Vigorous Exercise, fitness and incident hypertension, high cholesterol, and diabetes. Medicine and science in sports and Exercise. 2008;40(6):998.

24. Williams PT. Changes in vigorous physical activity and incident diabetes in male runners. Diabetes Care. 2007;30(11):2838-42.

25. Hughes VA, Fiatarone MA, Fielding RA, Kahn BB, Ferrara CM, Shepherd P, et al. Exercise increases muscle GLUT-4 levels and insulin action in subjects with impaired glucose tolerance. American Journal of Physiology-Endocrinology And Metabolism. 1993;264(6):E855-E62.

26. Larsen FJ, Anderson M, Ekblom B, Nyström T. Cardiorespiratory fitness predicts insulin action and secretion in healthy individuals. Metabolism. 2012;61(1):12-6.

27. Lynch J, Helmrich SP, Lakka TA, Kaplan GA, Cohen RD, Salonen R, et al. Moderately intense physical activities and high levels of cardiorespiratory fitness reduce the risk of non-insulin-dependent diabetes mellitus in middle-aged men. Archives of internal medicine. 1996;156(12):1307-14.

28. Okada K, Hayashi T, Tsumura K, Suematsu C, Endo G, Fujii S. Leisure-time physical activity at weekends and the risk of Type 2 diabetes mellitus in Japanese men: the Osaka Health Survey. Diabetic Medicine. 2000;17(1):53-8.

29. OHLSON L. The influence of body fat distributio on the incidence of diabetes mellitus: 13.5 years of follow up of the participants in the study of menborn in 1913. Diabetes. 1985;34:126-32.

30. Yang J. Enhanced skeletal muscle for adequate glucose homeostasis. Progress in molecular biology and translational science. 121 : Elsevier; 2014. p. 133-63.

31. King D, Dalsky G, Staten M, Clutter W, Van Houten D, Holloszy J. Insulin action and secretion in endurance-trained and untrained humans. Journal of Applied Physiology. 1987;63(6):2247-52.

32. Bouchard C, An P, Rice T, Skinner JS, Wilmore JH, Gagnon J, et al. Familial aggregation of $\mathrm{V}$ o 2 max response to exercise training: results from the HERITAGE Family Study. Journal of applied physiology. 1999;87(3):1003-8.

33. Szendroedi J, Roden M. Mitochondrial fitness and insulin sensitivity in humans. Diabetologia. 2008;51(12):2155.

\section{Tables}

Table 1 Baseline characteristics of the study cohort 


\begin{tabular}{|c|c|c|c|c|c|c|}
\hline & Total & METs $<6$ & METs 6-9 & METs 10-11 & METs $\geq 12$ & \multirow{2}{*}{$\begin{array}{l}p- \\
\text { value }\end{array}$} \\
\hline & 8722 & $589(6.7 \%)$ & 3077 (35.3\%) & $2930(33.6 \%)$ & $2126(24.4 \%)$ & \\
\hline Age (year) & $45.9 \pm 12.06$ & $50.9 \pm 12.37$ & $48.4 \pm 11.87$ & $45.5 \pm 11.81$ & $41.3 \pm 10.96$ & $<.0001$ \\
\hline Gender (Male) & $5798(66.5 \%)$ & $254(43.1 \%)$ & $1410(45.8 \%)$ & 2157 (73.6\%) & 1977 (93.0\%) & $<.0001$ \\
\hline Height (cm) & $162.2 \pm 19.51$ & $157.8 \pm 18.52$ & $159.4 \pm 17.97$ & $164.2 \pm 17.85$ & $165.0 \pm 23.49$ & $<.0001$ \\
\hline Weight (kg) & $79.7 \pm 16.55$ & $81.7 \pm 18.08$ & $81.3 \pm 17.51$ & $79.5 \pm 16.52$ & $77.2 \pm 14.11$ & $<.0001$ \\
\hline BMI $\left(\mathrm{kg} / \mathrm{m}^{2}\right)$ & $29.4 \pm 6.15$ & $32.3 \pm 7.22$ & $31.2 \pm 6.58$ & $28.5 \pm 5.23$ & $26.9 \pm 5.10$ & $<.0001$ \\
\hline \multicolumn{7}{|l|}{$\begin{array}{l}\text { Cardiovascular risk } \\
\text { factors }\end{array}$} \\
\hline Hypertension & $2955(33.9 \%)$ & $258(43.8 \%)$ & $1154(37.5 \%)$ & $987(33.7 \%)$ & $556(26.2 \%)$ & $<.0001$ \\
\hline Hyperlipidaemia & $2465(28.3 \%)$ & $172(29.2 \%)$ & $880(28.6 \%)$ & $884(30.2 \%)$ & 529 (24.9\%) & 0.0005 \\
\hline Known CAD & 474 (5.4\%) & $27(4.6 \%)$ & 157 (5.1\%) & $184(6.3 \%)$ & $106(5.0 \%)$ & 0.0938 \\
\hline Known CHF & $66(0.8 \%)$ & $4(0.7 \%)$ & $30(1.0 \%)$ & $23(0.8 \%)$ & $9(0.4 \%)$ & 0.1593 \\
\hline Prior CABG & $131(1.5 \%)$ & 10 (1.7\%) & $57(1.9 \%)$ & $43(1.5 \%)$ & $21(1.0 \%)$ & 0.0885 \\
\hline Prior MI & $454(5.2 \%)$ & $30(5.1 \%)$ & 151 (4.9\%) & $172(5.9 \%)$ & $101(4.8 \%)$ & 0.2524 \\
\hline Prior PCl & $306(3.5 \%)$ & $16(2.7 \%)$ & $92(3.0 \%)$ & $123(4.2 \%)$ & 75 (3.5\%) & 0.0538 \\
\hline Smoking & 277 (3.2\%) & $34(5.8 \%)$ & $88(2.9 \%)$ & 107 (3.7\%) & $48(2.3 \%)$ & $<.0001$ \\
\hline Lung disease & $348(4.0 \%)$ & $37(6.3 \%)$ & $145(4.7 \%)$ & $124(4.2 \%)$ & $42(2.0 \%)$ & $<.0001$ \\
\hline \multicolumn{7}{|l|}{ Lab results* } \\
\hline Cholesterol & $4.6(3.87,5.30)$ & $4.4(3.80,5.20)$ & $4.5(3.84,5.28)$ & $4.5(3.87,5.33)$ & $4.6(3.95,5.35)$ & 0.0142 \\
\hline Triglyceride & $1.4(0.99,1.86)$ & $1.4(1.04,1.94)$ & $1.3(0.98,1.82)$ & $1.4(0.98,1.89)$ & $1.4(1.02,1.91)$ & 0.0128 \\
\hline HDL & $1.0(0.88,1.22)$ & $1.0(0.87,1.22)$ & $1.1(0.90,1.25)$ & $1.0(0.87,1.22)$ & $1.0(0.88,1.18)$ & $<.0001$ \\
\hline LDL & $2.8(2.22,3.49)$ & $2.7(2.10,3.32)$ & $2.8(2.19,3.43)$ & $2.8(2.22,3.51)$ & $2.9(2.29,3.62)$ & $<.0001$ \\
\hline Haemoglobin & $143(129,154)$ & $133.0(121,144)$ & $136.0(123,148)$ & $146.0(132,156)$ & $152.0(142,160)$ & $<.0001$ \\
\hline Haematocrit & $0.4(0.39,0.46)$ & $0.4(0.37,0.43)$ & $0.4(0.37,0.44)$ & $0.4(0.40,0.46)$ & $0.4(0.42,0.47)$ & $<.0001$ \\
\hline Calcium & $2.3(2.25,2.40)$ & $2.3(2.20,2.35)$ & $2.3(2.23,2.39)$ & $2.3(2.25,2.39)$ & $2.4(2.28,2.42)$ & $<.0001$ \\
\hline BUN & $4.6(3.80,5.80)$ & $4.5(3.60,6.00)$ & $4.5(3.60,5.80)$ & $4.7(3.80,5.80)$ & $4.8(4.00,5.80)$ & $<.0001$ \\
\hline Creatinine & $75.0(64.00,89.00)$ & $69.5(60.00,85.00)$ & $70.0(60.00,84.00)$ & $75.0(65.00,88.00)$ & $81.0(72.00,93.00)$ & $<.0001$ \\
\hline eGFR & $\begin{array}{l}94.7(80.39 \\
109.42)\end{array}$ & $\begin{array}{l}92.8(77.29 \\
106.46)\end{array}$ & $\begin{array}{l}93.7(78.85 \\
107.83)\end{array}$ & $\begin{array}{l}95.8(81.84, \\
110.79)\end{array}$ & $\begin{array}{l}94.3(81.44 \\
110.09)\end{array}$ & 0.0001 \\
\hline hsCRP & $2.5(0.93,5.00)$ & $6.0(2.78,11.00)$ & $3.5(1.24,6.16)$ & $2.7(0.85,5.00)$ & $1.4(0.78,2.38)$ & 0.0001 \\
\hline Vitamin-D & $32.9(23.00,48.00)$ & $29.8(21.00,47.00)$ & $33.0(22.20,49.00)$ & $33.3(23.15,49.40)$ & $32.6(23.90,46.00)$ & 0.0001 \\
\hline \multicolumn{7}{|l|}{ Medications } \\
\hline Beta-blockers & $710(8.1 \%)$ & $61(10.4 \%)$ & $268(8.7 \%)$ & $247(8.4 \%)$ & $134(6.3 \%)$ & 0.0017 \\
\hline Calcium channel blockers & $503(5.8 \%)$ & $54(9.2 \%)$ & $202(6.6 \%)$ & $159(5.4 \%)$ & $88(4.1 \%)$ & $<.0001$ \\
\hline ACEI & $512(5.9 \%)$ & $40(6.8 \%)$ & 177 (5.8\%) & 191 (6.5\%) & $104(4.9 \%)$ & 0.0753 \\
\hline ARB & 988 (11.3\%) & 86 (14.6\%) & 386 (12.5\%) & 341 (11.6\%) & $175(8.2 \%)$ & $<.0001$ \\
\hline ACEARB & $1288(14.8 \%)$ & $107(18.2 \%)$ & 489 (15.9\%) & $452(15.4 \%)$ & $240(11.3 \%)$ & $<.0001$ \\
\hline Aspirin & 875 (10.0\%) & $60(10.2 \%)$ & 309 (10.0\%) & $328(11.2 \%)$ & $178(8.4 \%)$ & 0.0123 \\
\hline Digoxin & $48(0.6 \%)$ & $7(1.2 \%)$ & $20(0.6 \%)$ & $12(0.4 \%)$ & $9(0.4 \%)$ & 0.0847 \\
\hline PPI & 744 (8.5\%) & 59 (10.0\%) & $271(8.8 \%)$ & $284(9.7 \%)$ & 130 (6.1\%) & $<.0001$ \\
\hline Plavix & $2057(23.6 \%)$ & $149(25.3 \%)$ & $718(23.3 \%)$ & 717 (24.5\%) & $473(22.2 \%)$ & 0.2169 \\
\hline Statin & 1388 (15.9\%) & $86(14.6 \%)$ & 483 (15.7\%) & 506 (17.3\%) & $313(14.7 \%)$ & 0.0674 \\
\hline
\end{tabular}

Page $7 / 12$ 


\begin{tabular}{|c|c|c|c|c|c|c|}
\hline Diuretic & $357(4.1 \%)$ & $41(7.0 \%)$ & $154(5.0 \%)$ & $110(3.8 \%)$ & $52(2.4 \%)$ & $<.0001$ \\
\hline \multicolumn{7}{|l|}{ Stress test results } \\
\hline Rest HR (bpm) & $81.9 \pm 16.12$ & $86.9 \pm 18.45$ & $84.8 \pm 17.00$ & $81.1 \pm 15.05$ & $77.5 \pm 14.21$ & $<.0001$ \\
\hline Peak HR (bpm) & $155.5 \pm 22.13$ & $130.9 \pm 25.28$ & $149.8 \pm 21.76$ & $158.5 \pm 18.79$ & $166.7 \pm 17.53$ & $<.0001$ \\
\hline Rest SBP (mmHg) & $129.8 \pm 16.94$ & $133.0 \pm 19.06$ & $130.7 \pm 18.34$ & $129.1 \pm 16.04$ & $128.4 \pm 14.98$ & $<.0001$ \\
\hline Peak SBP (mmHg) & $160.8 \pm 25.92$ & $152.7 \pm 32.48$ & $160.7 \pm 28.64$ & $162.4 \pm 24.55$ & $160.7 \pm 21.29$ & $<.0001$ \\
\hline Rest DBP (mmHg) & $79.2 \pm 9.88$ & $79.5 \pm 10.07$ & $78.6 \pm 10.38$ & $79.6 \pm 9.45$ & $79.5 \pm 9.62$ & 0.0034 \\
\hline Peak DBP (mmHg) & $82.8 \pm 10.63$ & $82.3 \pm 10.89$ & $83.4 \pm 10.77$ & $83.4 \pm 10.76$ & $81.2 \pm 10.06$ & $<.0001$ \\
\hline Peak METs & $10.1 \pm 2.80$ & $4.7 \pm 0.95$ & $8.0 \pm 1.04$ & $10.7 \pm 0.62$ & $13.6 \pm 1.48$ & $<.0001$ \\
\hline $\begin{array}{l}\text { Chronotropic } \\
\text { Incompetence }\end{array}$ & $2275(26.1 \%)$ & $391(66.4 \%)$ & $1013(32.9 \%)$ & $591(20.2 \%)$ & $280(13.2 \%)$ & $<.0001$ \\
\hline Duke Treadmill Score & $5.5 \pm 6.12$ & $1.8 \pm 5.79$ & $4.0 \pm 5.43$ & $6.2 \pm 5.73$ & $7.9 \pm 6.56$ & $<.0001$ \\
\hline Low & $6040(69.3 \%)$ & $114(19.4 \%)$ & $2064(67.1 \%)$ & $2221(75.8 \%)$ & $1641(77.2 \%)$ & $<.0001$ \\
\hline Moderate & 2447 (28.1\%) & $454(77.1 \%)$ & $925(30.1 \%)$ & $597(20.4 \%)$ & $471(22.2 \%)$ & \\
\hline High & $235(2.7 \%)$ & $21(3.6 \%)$ & $88(2.9 \%)$ & $112(3.8 \%)$ & $14(0.7 \%)$ & \\
\hline \multicolumn{7}{|c|}{$\begin{array}{l}\text { CAD: Coronary artery disease, CHF: Congestive heart failure, CABG: Coronary artery bypass grafting, MI: Myocardial infarction, PCI: Percutaneous } \\
\text { coronary intervention, HDL: High density lipoprotein, LDL: Low density lipoprotein, BUN: Blood urea nitrogen, eGFR: estimated Glomerular filtration } \\
\text { rate, ACEI: Angiotensin converting enzyme inhibitors, ARB: Angiotensin Receptor blocker, PPI: Proton pump inhibitors, HR: Heart rate, SBP: Systolic } \\
\text { blood pressure, DBP: Diastolic blood pressure, METs: Metabolic equivalent of tasks. }\end{array}$} \\
\hline
\end{tabular}

Table 2 


\begin{tabular}{|c|c|c|c|c|c|c|c|c|c|c|c|c|c|c|c|}
\hline & \multicolumn{3}{|c|}{ Model (1) } & \multicolumn{3}{|c|}{ Model (2) } & \multicolumn{3}{|c|}{ Model (3) } & \multicolumn{3}{|c|}{ Model (4A) } & \multicolumn{3}{|c|}{ Model (4B) } \\
\hline AIC & \multicolumn{3}{|c|}{36619.287} & \multicolumn{3}{|c|}{36573.79} & \multicolumn{3}{|c|}{36408.081} & \multicolumn{3}{|c|}{36253.129} & \multicolumn{3}{|c|}{36227.135} \\
\hline C-Statistics & \multicolumn{3}{|l|}{0.6221} & \multicolumn{3}{|l|}{0.6289} & \multicolumn{3}{|c|}{0.6581} & \multicolumn{3}{|l|}{0.6817} & \multicolumn{3}{|c|}{0.6839} \\
\hline IAUC & \multicolumn{3}{|l|}{0.6256} & \multicolumn{3}{|l|}{0.6352} & \multicolumn{3}{|l|}{0.6581} & \multicolumn{3}{|l|}{0.6911} & \multicolumn{3}{|c|}{0.6948} \\
\hline NRI & \multicolumn{3}{|l|}{0.3757} & \multicolumn{3}{|l|}{0.2451} & \multicolumn{3}{|c|}{0.3562} & \multicolumn{3}{|l|}{0.1595} & \multicolumn{3}{|l|}{0.129} \\
\hline \multirow[t]{2}{*}{ IDI } & \multicolumn{3}{|l|}{0.0123} & \multicolumn{3}{|l|}{0.0019} & \multicolumn{3}{|c|}{0.0065} & \multicolumn{3}{|l|}{0.0026} & 0.0026 & & \\
\hline & HR & $\begin{array}{l}95 \% \\
\mathrm{Cl}\end{array}$ & $p$ & $\mathrm{HR}$ & $\begin{array}{l}95 \% \\
\mathrm{Cl}\end{array}$ & $p$ & HR & $\begin{array}{l}95 \% \\
\mathrm{Cl}\end{array}$ & $p$ & HR & $\begin{array}{l}95 \% \\
\mathrm{Cl}\end{array}$ & $p$ & HR & $\begin{array}{l}95 \% \\
\mathrm{Cl}\end{array}$ & $p$ \\
\hline Age (years) & 1.032 & )$^{1.03-}$ & $<.001$ & 1.028 & )$^{1.02-}$ & $<.001$ & 1.028 & $\begin{array}{l}1.02- \\
)^{1.03}\end{array}$ & $<.001$ & 1.022 & )$^{1.02-}$ & $<.001$ & 1.02 & $\begin{array}{l}1.02- \\
)^{1.02}\end{array}$ & $<.001$ \\
\hline $\begin{array}{l}\text { Gender Female } \\
\text { vs Male }\end{array}$ & 1.131 & )$^{1.03-}$ & 0.009 & 1.176 & $\begin{array}{l}1.07- \\
)^{1.29}\end{array}$ & 0.001 & 1.138 & $\begin{array}{l}1.04- \\
)^{1.25}\end{array}$ & 0.007 & 0.892 & $\begin{array}{l}( \\
0.81- \\
)^{0.99}\end{array}$ & 0.027 & 0.87 & 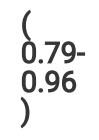 & 0.007 \\
\hline $\begin{array}{l}\text { Resting heart } \\
\text { rate (bpm) }\end{array}$ & 1.002 & )$^{1.00-}$ & 0.109 & 1.003 & $\begin{array}{l})^{1.00-} \\
)^{1.01}\end{array}$ & 0.011 & 1.004 & $\begin{array}{l}1.00- \\
)^{1.01}\end{array}$ & 0.003 & 1.002 & )$^{1.00-}$ & 0.109 & 1.001 & )$^{1.00-}$ & 0.452 \\
\hline $\begin{array}{l}\text { Cardiovascular } \\
\text { risk factors }\end{array}$ & & & & & & & & & & & & & & & \\
\hline Hypertension & & & & 1.189 & $\begin{array}{l})^{1.08-} \\
)^{1.31}\end{array}$ & 0.000 & 1.138 & $\begin{array}{l}1.03- \\
)^{1.26}\end{array}$ & 0.015 & 1.06 & $\begin{array}{l})^{0.95-} \\
)^{1.18}\end{array}$ & 0.284 & 1.059 & $\begin{array}{l}(.95- \\
)^{1.18}\end{array}$ & 0.293 \\
\hline Hyperlipidemia & & & & 1.196 & $\begin{array}{l})^{1.08-} \\
)^{1.32}\end{array}$ & 0.000 & 1.502 & $\begin{array}{l}(1.36- \\
)^{1.66}\end{array}$ & $<.001$ & 1.537 & )$^{1.39-}$ & $<.001$ & 1.539 & $\begin{array}{l})^{1.39-} \\
)^{1.71}\end{array}$ & $<.001$ \\
\hline Smoking & & & & 1.202 & $\begin{array}{l}(.94- \\
)^{1.54}\end{array}$ & 0.150 & 1.241 & $\begin{array}{l})^{0.97-} \\
)^{1.59}\end{array}$ & 0.090 & 1.19 & 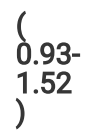 & 0.167 & 1.178 & $\begin{array}{l}( \\
)^{0.92-} \\
)^{1.51}\end{array}$ & 0.193 \\
\hline Lung disease & & & & 1.06 & $\begin{array}{l})^{0.77-} \\
)^{1.46}\end{array}$ & 0.720 & 0.961 & $\begin{array}{l}{ }^{0.69-} \\
)^{1.34}\end{array}$ & 0.814 & 0.94 & 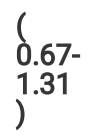 & 0.716 & 0.908 & $\begin{array}{l}( \\
0.65- \\
)^{1.27}\end{array}$ & 0.572 \\
\hline Known CAD & & & & 1.154 & $\begin{array}{l}\text { (..98- }^{1.36} \\
)^{1.96}\end{array}$ & 0.092 & 1.149 & $\begin{array}{l})^{0.97-} \\
)^{1.37}\end{array}$ & 0.117 & 1.18 & $\begin{array}{l})^{0.99-} \\
)^{1.40}\end{array}$ & 0.060 & 1.189 & $\begin{array}{l}(.00- \\
)^{1.41}\end{array}$ & 0.049 \\
\hline Known CHF & & & & 0.588 & $\begin{array}{l}\text { (d.36- } \\
)^{0.97}\end{array}$ & 0.039 & 0.483 & $\begin{array}{l}\text { ( } \\
\text { o.29- }^{0.81} \\
)^{-8}\end{array}$ & 0.005 & 0.431 & 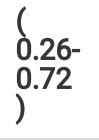 & 0.001 & 0.429 & $\begin{array}{l}\text { (.26- } \\
0.71 \\
)^{0.26}\end{array}$ & 0.001 \\
\hline Medications & & & & & & & & & & & & & & & \\
\hline Statins & & & & & & & 0.332 & $\begin{array}{l}\hat{l}^{0.28-} \\
0.40\end{array}$ & $<.001$ & 0.338 & $\begin{array}{l}\left(\begin{array}{l} \\
0.28- \\
0.41\end{array}\right. \\
\end{array}$ & $<.001$ & 0.338 & $\begin{array}{l}( \\
0.28- \\
0.41\end{array}$ & $<.001$ \\
\hline PPI & & & & & & & 1.632 & $\begin{array}{l}\mathfrak{l}^{1.32-} \\
\mathfrak{2}^{.01}\end{array}$ & $<.001$ & 1.563 & )$^{1.27-}$ & $<.001$ & 1.568 & $\begin{array}{l}1.27- \\
)^{1.94}\end{array}$ & $<.001$ \\
\hline CCB & & & & & & & 0.994 & $\begin{array}{l}\text { (..81- }^{1.21} \\
)^{-1}\end{array}$ & 0.955 & 1.005 & $\begin{array}{l})^{0.82-} \\
)^{1.23}\end{array}$ & 0.964 & 0.999 & $\begin{array}{l}(.82- \\
)^{1.22}\end{array}$ & 0.993 \\
\hline BB & & & & & & & 1.697 & $\begin{array}{l}\mathfrak{l}^{1.38-} \\
2.09\end{array}$ & $<.001$ & 1.615 & $\begin{array}{l})^{1.31-} \\
)^{1.99}\end{array}$ & $<.001$ & 1.588 & $\begin{array}{l})^{1.29-} \\
)^{1.96}\end{array}$ & $<.001$ \\
\hline
\end{tabular}




\begin{tabular}{|c|c|c|c|c|c|c|c|c|c|}
\hline ACEARB & 0.996 & $\begin{array}{l}\text { (.86- } \\
)^{1.15}\end{array}$ & 0.951 & 0.979 & $\begin{array}{l}\text { (.85- } \\
1.13\end{array}$ & 0.771 & 0.988 & $\begin{array}{l}\text { (.86- } \\
1.14\end{array}$ & 0.866 \\
\hline Diuretic & 1.187 & $\begin{array}{l}\text { (.95- } \\
1.48 \\
)^{-4}\end{array}$ & 0.124 & 1.182 & $\begin{array}{l}\text { (.95- } \\
1.47\end{array}$ & 0.138 & 1.164 & $\begin{array}{l}\text { (.93- } \\
1.45\end{array}$ & 0.178 \\
\hline \multicolumn{10}{|l|}{$\begin{array}{l}\text { METs } \\
\text { (Categories) }\end{array}$} \\
\hline METs 6-9 & & & & 0.871 & $\begin{array}{l}(.75- \\
1.01 \\
)^{(.01}\end{array}$ & 0.073 & & & \\
\hline METs 10-11 & & & & 0.619 & $\begin{array}{l}( \\
0.52- \\
0.73\end{array}$ & $<.001$ & & & \\
\hline METs $\geq 12$ & & & & 0.482 & 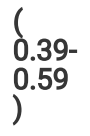 & $<.001$ & & & \\
\hline $\begin{array}{l}\text { METs } \\
\text { (Continuous) }\end{array}$ & & & & & & & 0.9 & $\begin{array}{l}\text { (o.88- } \\
0.92\end{array}$ & $<.001$ \\
\hline $\begin{array}{l}\text { Chronotropic } \\
\text { incompetence }\end{array}$ & & & & 1.119 & $\begin{array}{l}(1.01- \\
1.24\end{array}$ & 0.030 & 1.056 & $\begin{array}{l}\text { (.95- } \\
1.17\end{array}$ & 0.303 \\
\hline \multicolumn{10}{|l|}{$\begin{array}{l}\text { Duke Risk } \\
\text { Score }\end{array}$} \\
\hline High Risk & & & & 1.293 & $\begin{array}{l}(1.00- \\
1.67\end{array}$ & 0.048 & 1.257 & $\begin{array}{l}\text { ( } \\
0.97- \\
1.62\end{array}$ & 0.078 \\
\hline Moderate Risk & & & & 1.26 & $\begin{array}{l}(1.14- \\
1.39\end{array}$ & $<.001$ & 1.21 & $\begin{array}{l}1.10- \\
1.33\end{array}$ & $<.001$ \\
\hline
\end{tabular}

\section{Figures}




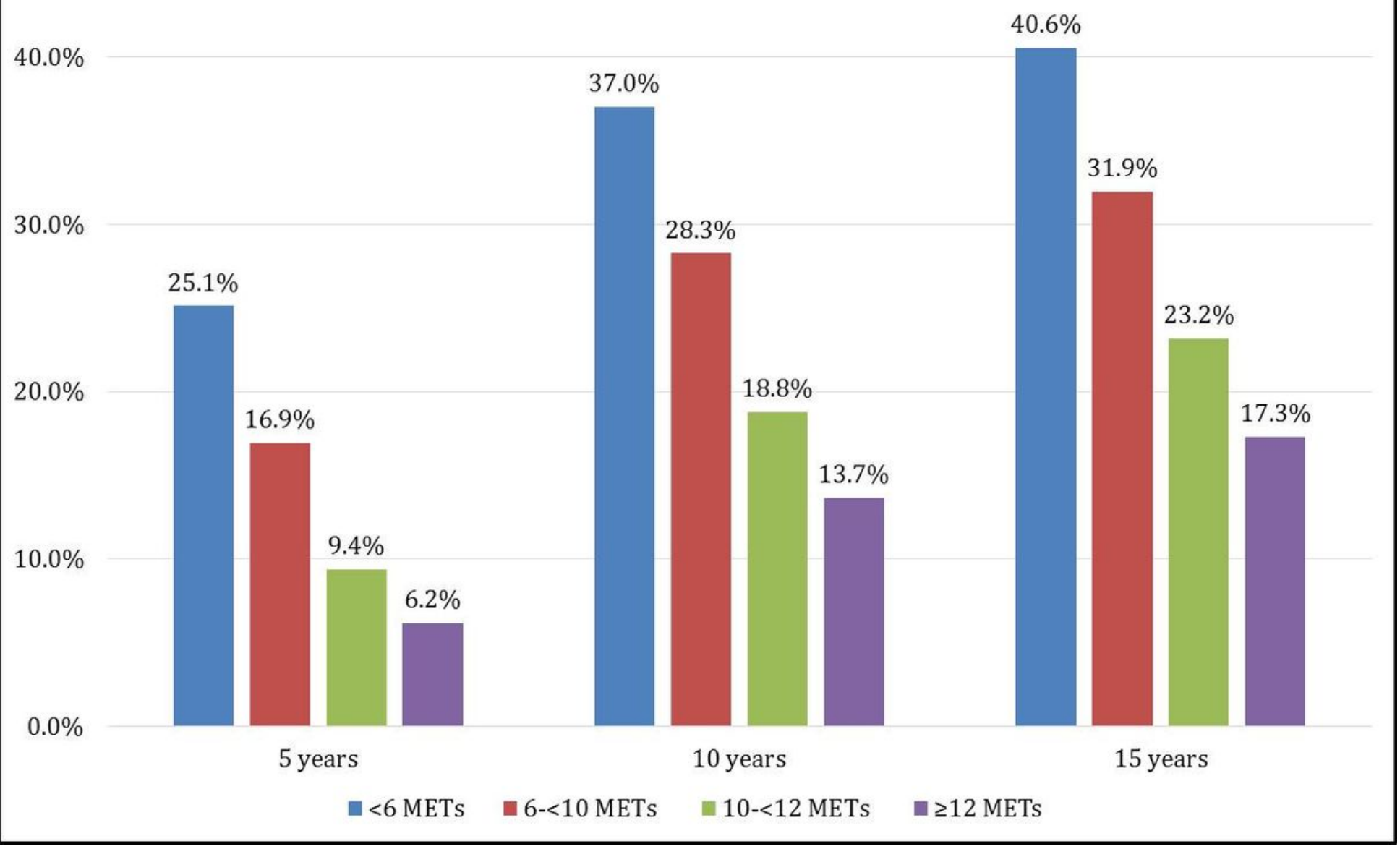

Figure 1

The cumulative rates of incidence diabetes.

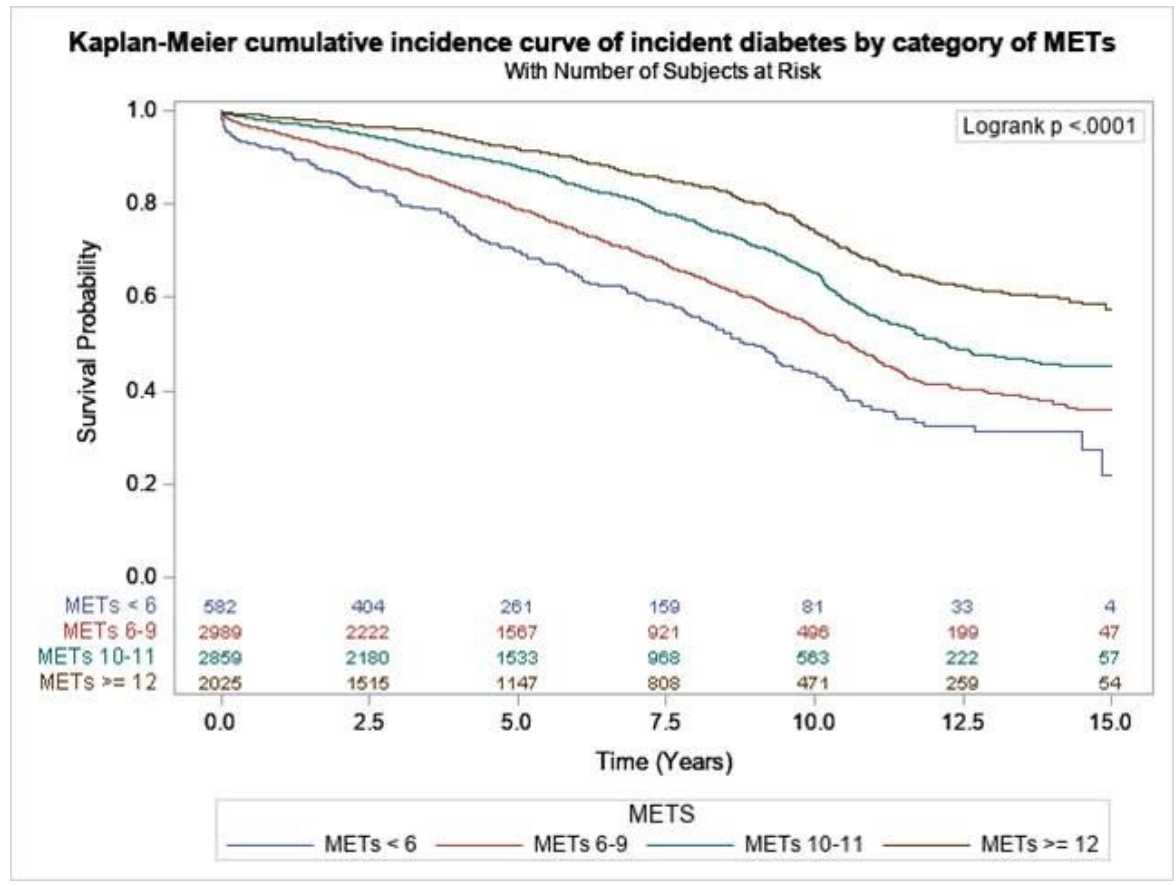

Figure 2

Kaplan-Meier cumulative incidence curve and the trends across categories of METs. 


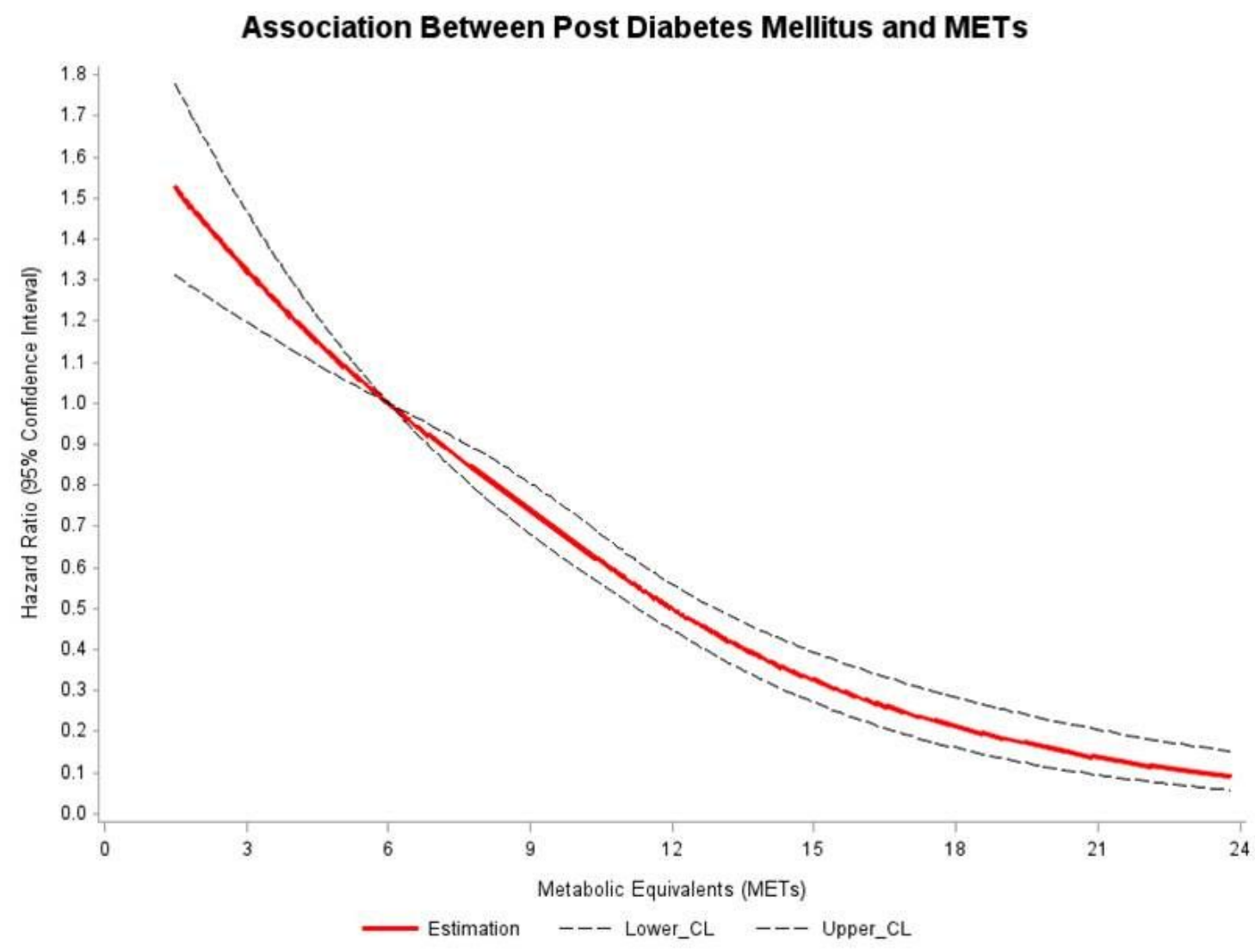

Figure 3

The relationship of incidence diabetes risk observed for every improvement of exercise capacity.

\section{Supplementary Files}

This is a list of supplementary files associated with this preprint. Click to download.

- SupplimentaryTable.docx 